\title{
Photoirradiation Caused Controllable Wettability Switching of Sputtered Highly Aligned $c$-Axis-Oriented Zinc Oxide Columnar Films
}

\author{
P. W. Chi, C. W. Su, B. H. Jhuo, and D. H. Wei \\ Institute of Manufacturing Technology and Department of Mechanical Engineering, National Taipei University of \\ Technology (TAIPEI TECH), Taipei 10608, Taiwan \\ Correspondence should be addressed to D. H. Wei; dhwei@ntut.edu.tw
}

Received 3 May 2014; Accepted 11 June 2014; Published 20 July 2014

Academic Editor: Ho Chang

Copyright (C) 2014 P. W. Chi et al. This is an open access article distributed under the Creative Commons Attribution License, which permits unrestricted use, distribution, and reproduction in any medium, provided the original work is properly cited.

\begin{abstract}
This study presents the microstructure morphology and UV photoirradiation coupling effects of the c-axis-oriented zinc oxide ( $\mathrm{ZnO})$ columnar films. Highly aligned c-axis-oriented films have been deposited onto glass substrates at room temperature by radio-frequency (RF) magnetron sputtering without introducing any oxygen source under different sputtering powers ranging from 50 to $150 \mathrm{~W}$. Self-assembled $\mathrm{ZnO}$ columnar structures that were successfully obtained belong to wurtzite structure, and the corresponding columnar structures and crystalline orientation were confirmed by the FE-SEM and XRD, respectively. All the ZnO columnar films exhibit good transparency with a visible light averaged transmittance over $82 \%$. According to water contact angle (CA) measurement, $\mathrm{ZnO}$ columnar films exhibit hydrophobic behavior. After exposing to photoirradiation under ultraviolet (UV) environment, all the $\mathrm{ZnO}$ samples showed remarkable transition from hydrophobic to superhydrophilic surfaces and could return to their original hydrophobicity after being placed in the dark. It is demonstrated that the controllable wettability of $\mathrm{ZnO}$ columnar films under changing between the UV photoirradiation and dark storage is due to the surface charges accumulation and discharging processes. As a result, this study could provide important applications for many fields such as ZnO-based hybrid sensors/solar cells functional devices with photoirradiation disinfection surfaces accompanied with reversible wettability switches.
\end{abstract}

\section{Introduction}

Self-cleaning is a special mechanism of surface property; it relates with the chemical composition and surface morphology. It has been focused for many potential applications, such as environmental cleanup $[1,2]$ and optoelectronic devices [3-5]. The photocatalytic behavior, in which the coating reacts with daylight to decompose dirt and hydrophilic action, in which water spreads on the surface, cleans up the dirt without any traces of water. Therefore, those two actions have quite important roles in self-cleaning effect [6-10]. Solar energy represents a probable renewable energy that includes visible and ultraviolet regions which is an important factor of driving photocatalytic process due to its high efficiency, low cost, and stability. However, oxide-based hybrid self-cleaning nanodevices have deeply potential of all renewable energies $[11,12]$.
The lotus leaves demonstrate high water contact angle, as high as $160^{\circ}$ due to their particular surface nanoscale structures [13-17]. Thus, the surface roughness plays an important role in wettability of bulk solid materials, and the hydrophobic materials are usually prepared by modifying surface with low surface energy for forming nanostructures. The multifunctional $\mathrm{ZnO}$ compound with the lowest surface free energy of the most densely packed (0002) planes in the wurtzite structure can easily form nanoscale products, which is also a good choice for self-cleaning coating.

The control of wettability transition for several special materials from hydrophilic to hydrophobic could via optical, mechanical, and chemical modifications [18-23]. Recently, several metal oxide semiconductors such as $\mathrm{TiO}_{2}, \mathrm{~V}_{2} \mathrm{O}_{5}$, and $\mathrm{ZnO}$ have been widely explored and controlled with exhibiting switchable wettability from hydrophilic to hydrophobic via different external factors such as $\mathrm{pH}$ value, exposure to 
light-induced irradiation, electric field, and heat treatment and then stored in different environment processes. Among them, the light irradiation is especially attractive because of its flexible on- and off-switching, remote control, and other advantages for potential industrial applications. This special property has attracted much focused attention due to its great advantages in applications such as self-cleaning device, antifogging glass, smart window, and construction materials just only controlled by reversible-switching wettability [24, 25].

$\mathrm{ZnO}$ and $\mathrm{TiO}_{2}$ are general materials for photocatalysts among the above metal oxides; both of them react under ultraviolet (UV) light due to their large band gaps of 3.37 and $3.2 \mathrm{ev}[26,27]$, respectively, and their wettability could be modified significantly by irradiation with UV light [28, 29]. Among these two materials, $\mathrm{ZnO}$ can easily form nanostructure. There are many reports about a reversible light-controlled hydrophobic/hydrophilic process for $\mathrm{ZnO}$ based thin film and nanostructures [30-32]. ZnO has direct wide band gap (3.37 ev) and high exciton binding energy (60 mev) and is optically transparent for visible light. It is therefore an expected material for many novel applications such as piezoelectric transducers, transparent thin film transistors, chemical gas sensors or biosensors [33-35], solar cells, and UV detectors [36-38]. According to the above functionalities, $\mathrm{ZnO}$ can provide a hydrophobic surface, which may be transformed into hydrophilic surface by UV irradiation, which coexists with intrinsic semiconductor properties and a particular surface morphology [39-44]. As for the surface chemical property of $\mathrm{ZnO}$ compound, the tunable and reversible wettability was explained to be the competition results between desorption and adsorption of organic chains and hydroxyl groups rearrangement on the material surface. However, the $\mathrm{ZnO}$ nanostructures have highly developed surface properties and are expected to exhibit more advanced controllable wettability including a quickly hydrophilic/hydrophobic switch with tunable contact angles. There are many kinds of shapes, sizes and arrangements of $\mathrm{ZnO}$ nanostructures, including nanorods, nanopillars, nanowires, nanoneedles, and nanobelts. Many current scientific articles have been reported on different nanostructures, which were generally used to enhance the wetting effects on $\mathrm{ZnO}$ films, and some of them obtained the superhydrophobic surface.

In this research work, we investigated the self-cleaning properties of highly $c$-axis-oriented $\mathrm{ZnO}$ thin films, deposited at room temperature by radio-frequency (RF) sputtering system. The surface morphology and grain size were controlled by varying sputtering power conditions. The transparency for all highly $c$-axis-oriented $\mathrm{ZnO}$ thin films ranging from 50 to $150 \mathrm{~W}$ was also measured. The surface wettability of $\mathrm{ZnO}$ thin films was examined by water contact angle measurements. The switchable wettability was investigated by changing the conditions of UV photoirradiation exposure and dark room storage. This research work not only extends the scope of potential applications for $c$-axis-oriented $\mathrm{ZnO}$ columnar films, but also provides a profound understanding of UV modulated wettability of $\mathrm{ZnO}$ (0002) columnar films.

\section{Experimental Procedures}

A radio-frequency (RF) magnetron sputtering system was employed to deposit the $\mathrm{ZnO}$ thin films onto D263T glass substrates, and all the substrates were placed parallel to the $\mathrm{ZnO}$ ceramic target. $\mathrm{ZnO}$ target is composed of $99.99 \%$ purely pressed $\mathrm{ZnO}$ powder, and the size is of $0.075 \mathrm{~m}$ diameter and $0.006 \mathrm{~m}$ thickness. All the substrates were rinsed in deionized water, ultrasonically cleaned in ethanol and acetone to remove organic contamination, then dried in hot air before they load into the vacuum chamber. The sputtering chamber was pumped down to a base pressure of $3 \times 10^{-7}$ torr. Argon was filled into sputtering chamber sequentially with the low working pressure of $5 \times 10^{-3}$ torr. The $\mathrm{ZnO}$ thin films were deposited with different RF powers in the range of $50,75,100$, and $150 \mathrm{~W}$ at a fixed deposition time of 30 mins. The crystalline structure of $\mathrm{ZnO}$ thin films was characterized by X-ray diffraction (XRD, PANalytical X'Pert PRO MRD) with $\mathrm{Cu} \mathrm{K}_{\alpha}$ radiation $(\lambda=1.54 \AA)$ in the range of $2 \theta=20-60^{\circ}$. The surface morphology of $\mathrm{ZnO}$ thin films was observed by field emission scanning electron microscopy (FE-SEM, JEOL JSM-6500F). The surface topography and roughness values of $\mathrm{ZnO}$ thin films were further analyzed by the atomic force microscope (AFM, DI NS3a). The optical transmittance was recorded by using a UVVis-NIR spectrophotometer (MP100-ME). The wettability of $\mathrm{ZnO}$ thin films was estimated from the contact angle $\theta$ of water droplets onto each $\mathrm{ZnO}$ sample surface (Pentad FTA 125). After completing the UV photoirradiation, the water contact angle was measured on the irradiated surface by using a water droplet $(\sim 3 \mu \mathrm{L})$ and with a digital camera to record the droplet photos. The UV photoirradiation onto $\mathrm{ZnO}$ thin films was conducted by $1520 \mathrm{~mW} / \mathrm{cm}^{2}$ mercury arc lamp (HAMAMATSU-Deuterium L2D2) with a wavelength of $365 \mathrm{~nm}$, and all the $\mathrm{ZnO}$ samples were stored in air ambient after UV photoirradiation.

\section{Results and Discussion}

3.1. Crystalline Structure and Corresponding Preferred Orientation. Figure 1 shows the X-ray diffraction patterns for the $\mathrm{ZnO}$ thin films deposited onto glass substrates with different $\mathrm{RF}$ powers ranging from 50 to $150 \mathrm{~W}$ at a fixed deposition time of 30 mins, respectively. The XRD patterns show that all the samples exhibit only a strong peak located at $2 \theta=34.5^{\circ}$, which corresponds to the $\mathrm{ZnO}$ (0002) plane (JCPDS Card: 361451 ), indicating that highly aligned $c$-axis-oriented $\mathrm{ZnO}$ film possesses a hexagonal wurtzite structure. The intensity of (0002) diffraction peak increased with increasing RF power, which is due to the increase of total film thickness and improvement of film crystallinity with increasing RF power. It can be understood that when the $c$-axis-oriented $\mathrm{ZnO}$ films have greater film thickness, the diffraction intensity raised from the (0002) plane will be stronger. The similar phenomenon of the effect of deposition power on $\mathrm{ZnO}$ polycrystalline thin films was reported elsewhere $[45,46]$. The strong signal intensity of the (0002) diffraction peak from the (0002) plane is due to the lowest surface energy of the (0002) basal plane in $\mathrm{ZnO}$ phase, leading to a preferred 


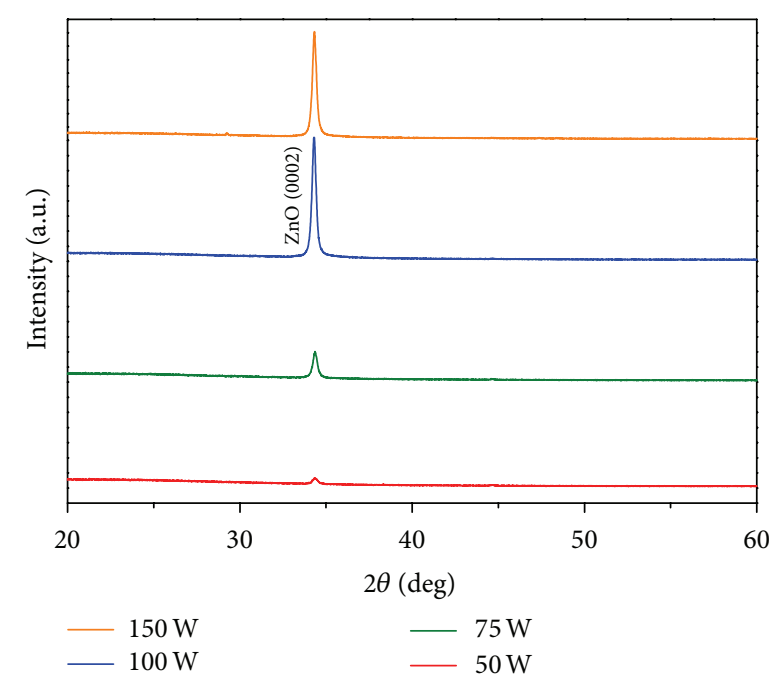

FIGURE 1: XRD patterns for the $\mathrm{ZnO}$ thin films deposited onto glass substrates at room temperature with RF deposition powers in the range of 50,75, 100, and $150 \mathrm{~W}$ at a fixed deposition time of $30 \mathrm{mins}$, respectively.

orientation perpendicular to (0001) plane. Therefore the $\mathrm{ZnO}$ films have been successfully deposited onto glass substrates at room temperature, and the crystalline quality degree of $c$ axis orientation could be controlled under optimum growth conditions.

\subsection{Top View and Cross-Sectional View Microstructures and} Corresponding Wettability Images. The top view SEM images for the $\mathrm{ZnO}$ thin films deposited onto glass substrates at room temperature with different RF powers ranged from 50 to $150 \mathrm{~W}$ as shown in Figures 2(a)-2(d). Figures 2(a)-2(d) show two different types of grain structures denoted by nanograin and submicrograin cases. The different grain structure was caused by different RF powers during the deposition process. The nanograin structure of $\mathrm{ZnO}$ thin films can be observed at lower RF powers (50 and $75 \mathrm{~W}$ ) as shown in Figures 2(a)-2(b). On the other hand, the submicrograin could be observed at higher deposition power of $150 \mathrm{~W}$ as shown in Figure 2(d). When the deposition power is $100 \mathrm{~W}$, the mixed nanograin and submicrograin structures of $\mathrm{ZnO}$ phases coexist in the microstructure as shown in Figure 2(c). Above results could be attributed to high plasma energy bombardment in which, leading to the grain transformation, the microstructure of the $\mathrm{ZnO}$ thin films could be controlled by the deposition power. It can be understood that, with increasing deposition power, the nanograins with multiple domains coalesce and connect to each other to conjoin into a big grain as shown in Figure 2(d). It also can be observed that apertures, which can trap air inside, present onto the surface of $\mathrm{ZnO}$ thin films.

The corresponding images for surface water contact angle measurement are shown in Figures $2(\mathrm{e})-2(\mathrm{~h})$, respectively. The surface water contact angle $(\mathrm{CA}, \theta)$ values are $71.3^{\circ}, 90.6^{\circ}$, $91.8^{\circ}$, and $71.6^{\circ}$ for each $\mathrm{ZnO}$ sample deposited at 50, 75, 100, and $150 \mathrm{~W}$, respectively. The $\mathrm{ZnO}$ samples show hydrophilic wetting at the depositing power of $50 \mathrm{~W}$, which is due to the fact that smooth surface and smaller grain size get fewer apertures that cannot provide the trapping of air as shown in Figure 2(e). While increasing depositing power up to $100 \mathrm{~W}$, the nanograin structure surface shows hydrophobic behavior, which is because large grain size and more apertures provide more trapping of air that reduces the contact area between water and smooth surface as shown in Figure 2(g). The small contact angle is observed from Figure 2(h), which is due to grain transformation from nanograin to submicrograin. This transformation caused the CA to decrease which was due to the less apertures formed at the depositing power of $150 \mathrm{~W}$ [47], and the contact angle $(\theta)$ was denoted as the interface angle measured between the liquid and solid surface.

The thickness values as a function of the $\mathrm{ZnO}$ thin films deposited onto glass substrates at room temperature with different RF powers ranged from 50 to $150 \mathrm{~W}$ and are shown in Figure 3(a). Figures 3(b) and 3(c) are the crosssectional micrographs of the $\mathrm{ZnO}$ thin films deposited at $\mathrm{RF}$ powers of 50 and $150 \mathrm{~W}$, respectively. The measured thickness values for $\mathrm{ZnO}$ thin films by cross-sectional SEM images were $65,104,301$, and $337 \mathrm{~nm}$ which corresponded to the deposition powers of 50,75, 100, and $150 \mathrm{~W}$, respectively. The thickness of $\mathrm{ZnO}$ thin films deposited onto glass substrates is increased with increasing the RF power. Figures $3(\mathrm{~b})$ and 3(c) showed the highly textured $\mathrm{ZnO}$ films perpendicular to (0001) plane. Typical self-assembled columnar structure of the $\mathrm{ZnO}$ films perpendicular to the glass substrate and with a hillock surface morphology was observed. Figures 3(b) and 3(c) also confirmed that thickness value of the $\mathrm{ZnO}$ films at the deposition power of $50 \mathrm{~W}$ was about $65 \mathrm{~nm}$ and at the deposition power of $150 \mathrm{~W}$ was $337 \mathrm{~nm}$, respectively.

Shown in Figures 4(a)-4(h) are the three-dimensional (3D) and the corresponded two-dimensional (2D) AFM micrographs $(1 \mu \mathrm{m} \times 1 \mu \mathrm{m})$. The surface topography images in either $2 \mathrm{D}$ or $3 \mathrm{D}$ images show the surface roughness of $\mathrm{ZnO}$ thin films increased with increasing the deposition power. The average surface roughness values (root mean square, RMS) of the $\mathrm{ZnO}$ thin films increase with increasing the deposition power. The average RMS values are $1.7 \mathrm{~nm}, 1.6 \mathrm{~nm}$, $3.3 \mathrm{~nm}$, and $5.6 \mathrm{~nm}$ for each $\mathrm{ZnO}$ sample deposited at 50, 75,100 , and $150 \mathrm{~W}$, respectively. Above results indicated that the high $c$-axis orientation $\mathrm{ZnO}$ (0002) thin films could provide the nanoscale surface roughness to demonstrate aperture formation which can trap the air. This kind of $\mathrm{ZnO}$ nanostructures could also provide nanometer-scale smoothness topography for suitable subsequent deposition of any top-electrode material onto its surface to function as a potential future sensing nanodevice [37].

Figures 5(a)-5(c) are the schematic diagram illustrations of the different types, showing the state of water droplet onto various surfaces of the $\mathrm{ZnO}$ thin films. Figure 5(a) is the smooth surface structure with hydrophilic wetting property for the $\mathrm{ZnO}$ thin films deposited at the lower powers of 50 and $75 \mathrm{~W}$, respectively, which is denoted as nanograin type. When the deposition power of the $\mathrm{ZnO}$ thin films is increased to $100 \mathrm{~W}$, the grain growth begins to form apertures that could provide the trapped air, which is denoted by a mixed nanograin and submicrograin type as shown in Figure 5(b). At the highest deposition power of $150 \mathrm{~W}$ for the $\mathrm{ZnO}$ thin 


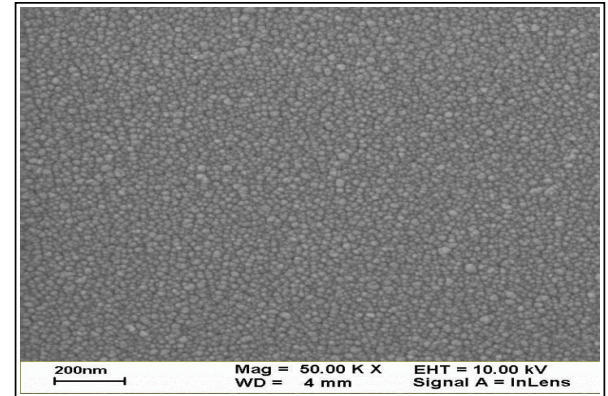

(a)

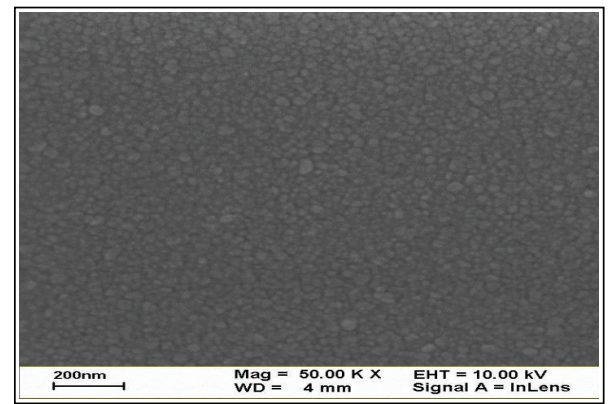

(b)

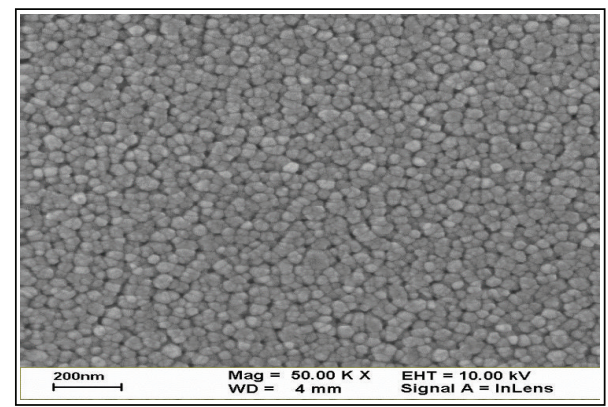

(c)

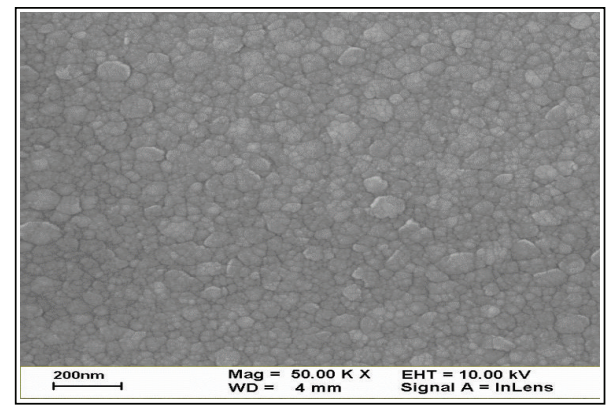

(d)

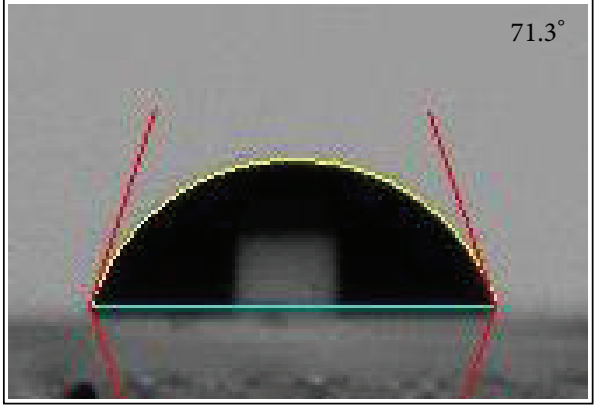

(e)

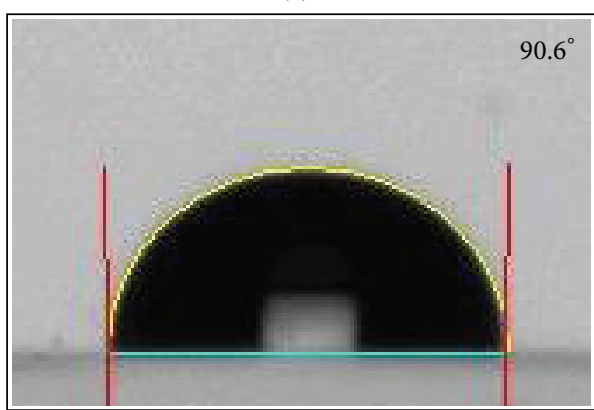

(f)

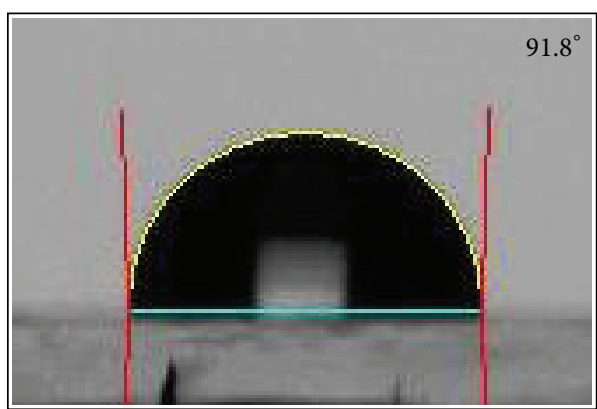

(g)

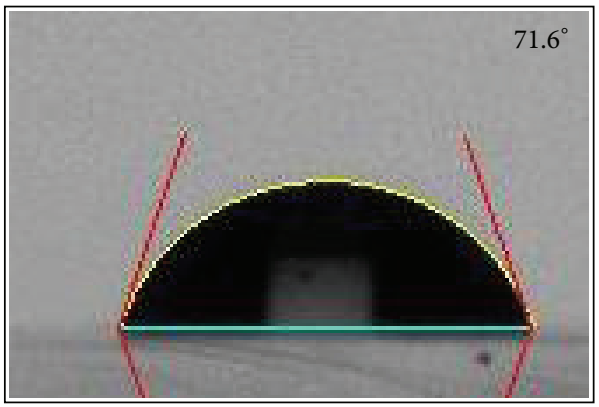

(h)

Figure 2: Top view SEM images for the ZnO thin films with deposition powers of (a) 50, (b) 75, (c) 100, and (d) $150 \mathrm{~W}$, respectively. The contact angle images for different $\mathrm{ZnO}$ thin films corresponded to the right side denoted by (e), (f), (g), and (h), respectively.

films, the formation of submicrograin microstructure gives more opportunity for the water droplet to contact with the surface area of the $\mathrm{ZnO}$ thin films, which is denoted by submicrograin type as shown in Figure 5(c).

In order to understand the wetting behavior of the $\mathrm{ZnO}$ thin films, we consider the typical Cassie-Baxter's (CB) equation that can be explained in this research work [48].
In the typical $\mathrm{CB}$ equation, the drops are suspended onto a hydrophobic surface with air trapped underneath as an incomplete filling and the equilibrium contact angle (CA, $\theta$ ) of a drop onto a nanostructure film can be described as

$$
\cos \theta^{\prime}=f_{1} \cos \theta+f_{2}
$$




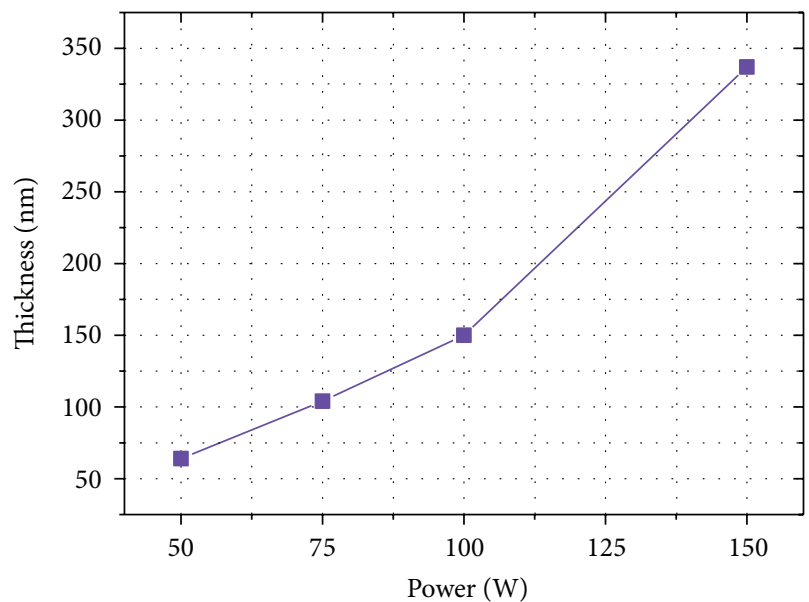

(a)

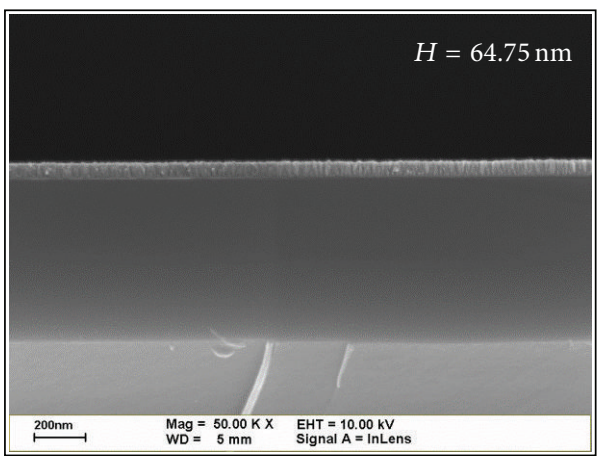

(b)

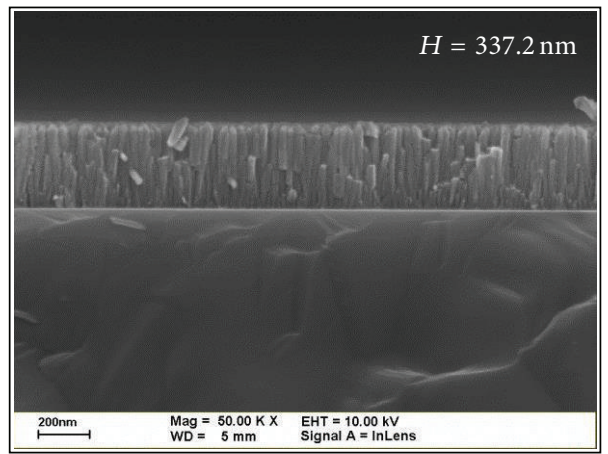

(c)

Figure 3: (a) The thickness values as a function of the $\mathrm{ZnO}$ thin films with different RF powers ranged from 50 to $150 \mathrm{~W}$. (b) and (c) are the cross-sectional micrographs for the $\mathrm{ZnO}$ thin films deposited at the RF powers of 50 and $150 \mathrm{~W}$, respectively.

where $f_{1}$ and $f_{2}$ are the area fractions of liquid-solid interface and liquid-air interface, respectively. As for $f_{1}+f_{2}=1$, (1) can be converted to

$$
\cos \theta^{\prime}=f_{1}(\cos \theta+1)-1,
$$

where $\theta$ is a constant that represents the CA on a smooth surface and $\theta^{\prime}$ is the CA on a rough surface. Based on (2), it can be understood that $\theta^{\prime}$ increases with decreasing the area fraction of liquid-solid interface $\left(f_{1}\right)$, and the surface fraction will make a significant contribution to CA. It is demonstrated that surface hydrophobicity improves when there is more air trapped between the liquid and solid surface exhibiting a larger CA as schematically shown in Figure 5(b). Therefore, more air is trapped between the water droplet and the surface of $\mathrm{ZnO}$ thin films. The $\mathrm{CA}$ of $\mathrm{ZnO}$ thin films will be much larger due to the fact that it prevents complete wetting of the surface. We have also explored the morphology and grain size effect on the controllable wettability of highly $c$-axis-oriented $\mathrm{ZnO}$ (0002) thin films, and the proposed mechanism was used to explain the related phenomena.

3.3. Optical Transmittance Measurement. Figure 6 shows the transparency of the $\mathrm{ZnO}$ thin films deposited onto glass substrates at room temperature with different $R F$ powers ranging from 50 to $150 \mathrm{~W}$. The oscillating property of spectrum is due to the formation of uniform and smooth surface for $\mathrm{ZnO}$ thin films, and it can be indicated to lead less light scattering [49]. As a result, all the highly $c$-axis-oriented $\mathrm{ZnO}$ columnar films deposited at room temperature with RF powers of 50, 75, 100, and $150 \mathrm{~W}$ have good transparency and exhibit a visible lightaveraged transmittance over $82 \%$. For the functional oxidebased coatings of self-disinfection glass or smart window combined with the hybrid devices such as sensors and solar cells, this high transmittance plays an important role in the particular industrial products application.

\subsection{Surface Wettability Switching for Self-Disinfection Caused} by UV Photoirradiation. According to the above results, the highly $c$-axis-oriented $\mathrm{ZnO}$ columnar film deposited at $\mathrm{RF}$ power of $100 \mathrm{~W}$ shows the best hydrophobicity. In order to change the wettability transition of the $\mathrm{ZnO}$ thin films, which was deposited onto glass substrate at RF power of $100 \mathrm{~W}$ at first, and then it was put under an ultraviolet (UV) light of wavelength $365 \mathrm{~nm}$, which could provide larger photon energy than the intrinsic band gap $(3.37 \mathrm{ev})$ of the $\mathrm{ZnO}$ phase. The relationship between the UV photoirradiation times varied from 1 to 60 mins and water contact angle (CA) for the $\mathrm{ZnO}$ thin films deposited at $100 \mathrm{~W}$ as shown in 


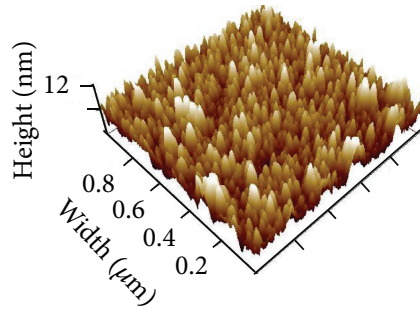

(a)

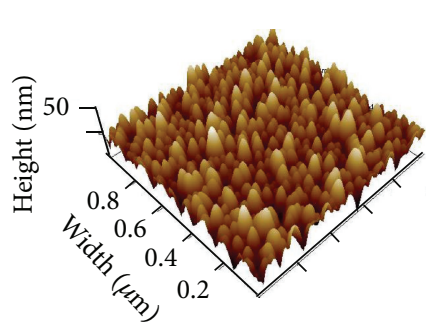

(e)

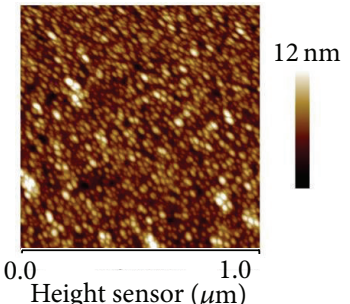

(b)

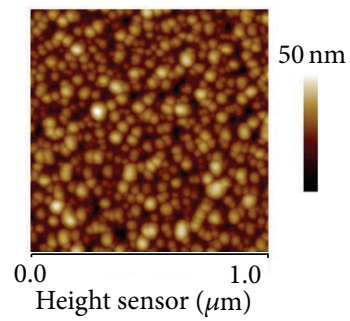

(f)

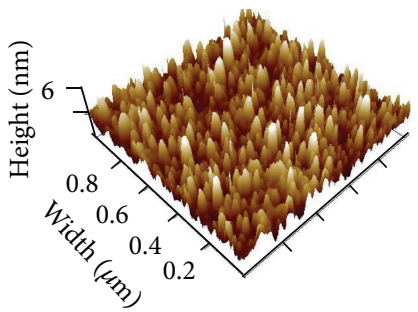

(c)

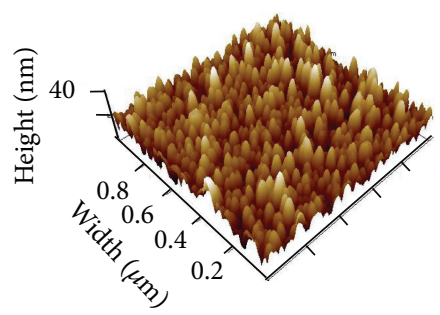

(g)

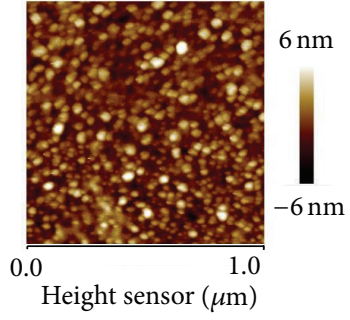

(d)

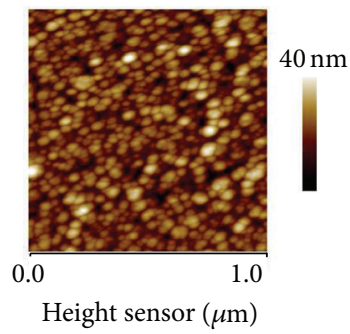

(h)

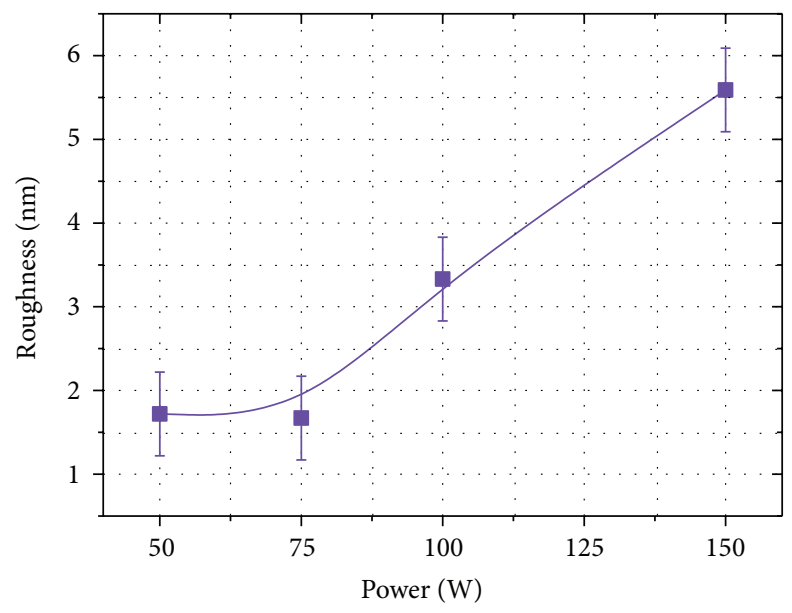

(i)

FIGURE 4: Atomic force microscope (AFM) 3D images for the ZnO thin films with different RF powers of (a) 50, (c) 75, (e) 100, and (g) 150 W; (b), (d), (f), and (h) are the corresponding 2D surface images for (a), (c), (e), and (g) forms, respectively. The scanning size of all domain images was fixed at $1 \times 1 \mu \mathrm{m}^{2}$. (i) The surface roughness values as a function of the $\mathrm{ZnO}$ thin films with different deposition powers ranged from 50 to $150 \mathrm{~W}$.

Figure 7. Inset showed the corresponding water CA images accompanied with the measured values for the $\mathrm{ZnO}$ (0002) columnar film. The $\mathrm{ZnO}$ sample deposited at RF power of $100 \mathrm{~W}$ was repeatedly measured after being stored in the dark for one day for reversing the initial wettability state. The CA values of $\mathrm{ZnO}$ columnar film decreased significantly with increasing the UV photoirradiation time, and the surface wettability was switched from hydrophobic to hydrophilic state. The $\mathrm{CA}$ value of $\mathrm{ZnO}$ columnar film deposited at $\mathrm{RF}$ power of $100 \mathrm{~W}$ changed from $91.8^{\circ}$ to $14.1^{\circ}$ after 60 mins of UV irradiation. The rapid decrease of CA value of $\mathrm{ZnO}$ phase can be attributed to the photocatalytic behavior caused by the accumulation of positive surface charges by photoelectron emission. The switching of wettability transition can also be explained by the following mechanism: via UV photoirradiation by photon energy, higher than or equal to the band gap of $\mathrm{ZnO}$ phase, the electrons $\left(\mathrm{e}^{-}\right)$in the valence band are excited to the conduction band. At the same time, the same number of holes $\left(\mathrm{h}^{+}\right)$generated in valence band.

$$
\mathrm{ZnO}+2 \mathrm{hv} \longrightarrow 2 \mathrm{~h}^{+}+2 \mathrm{e}^{-}
$$

Some of the holes react with lattice oxygen $\left(\mathrm{O}^{2-}\right)$ or surface oxygen atoms to form surface oxygen vacancies $\mathrm{O}^{1-}$, while some of the electrons react with lattice metal ions $\left(\mathrm{Zn}^{2+}\right)$ to form $\mathrm{Zn}^{2+}$ defective sites, as listed in the following equations:

$$
\mathrm{O}^{2-}+\mathrm{h}^{+} \longrightarrow \mathrm{O}^{1-} \text { (surface trapped hole) }
$$




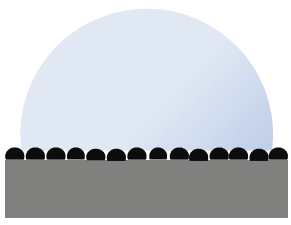

(b)

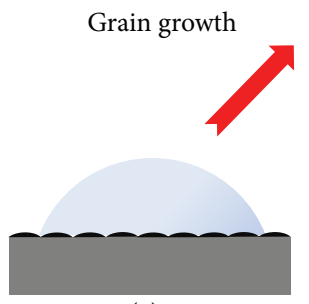

(a)

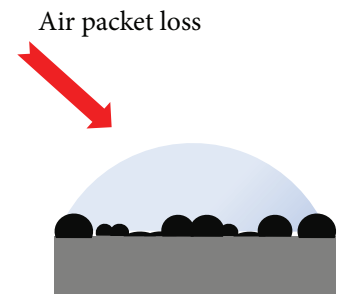

(c)
FIgURE 5: Schematic diagrams illustrating the $\mathrm{ZnO}$ films with different scales of grain size induced by different deposition powers: (a) nanograin (50 and $75 \mathrm{~W}$ ), (b) mixed nanograin and submicrograin $(100 \mathrm{~W})$, and $(\mathrm{c})$ submicrograin $(150 \mathrm{~W})$ types, respectively.

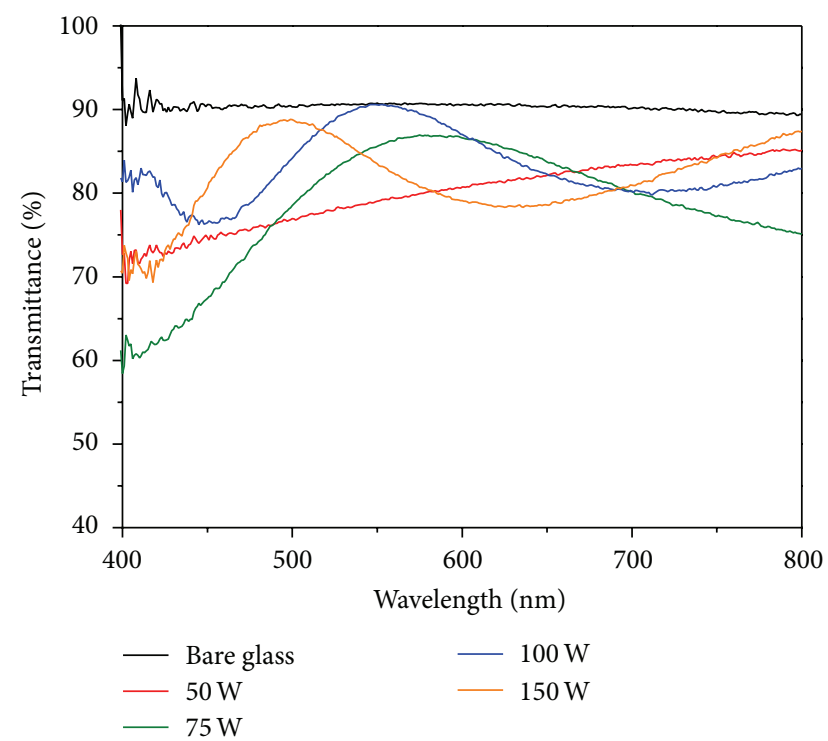

Figure 6: Optical transmittance spectra for the pure-bare glass substrate and $\mathrm{ZnO}$ thin films with different $\mathrm{RF}$ powers ranged from 50 to $150 \mathrm{~W}$, respectively.

$$
\begin{array}{r}
\mathrm{Zn}^{2+}+\mathrm{e}^{-} \longrightarrow \mathrm{Zn}^{+} \text {(surface trapped electron) } \\
\mathrm{O}^{1-}+\mathrm{h}^{+} \longrightarrow \frac{1}{2} \mathrm{O}_{2} \text { (gas) }+\mathrm{V}_{\mathrm{O}} \text { (oxygen vacancy) }
\end{array}
$$

The water molecules and oxygen may compete with each other to dissociatively be absorbed on the defective sites. The surface trapped electrons $\left(\mathrm{Zn}^{+}\right)$tend to react with oxygen molecules adsorbed on the surface as follows:

$$
\mathrm{Zn}+\mathrm{O}_{2} \longrightarrow \mathrm{Zn}^{2+}+\mathrm{O}^{2-}
$$

At the same time, the water molecules may act in concert with oxygen vacancy sites $\left(\mathrm{V}_{\mathrm{O}}\right)$, which cause the dissociative adsorption of the water molecules onto the $\mathrm{ZnO}$ film

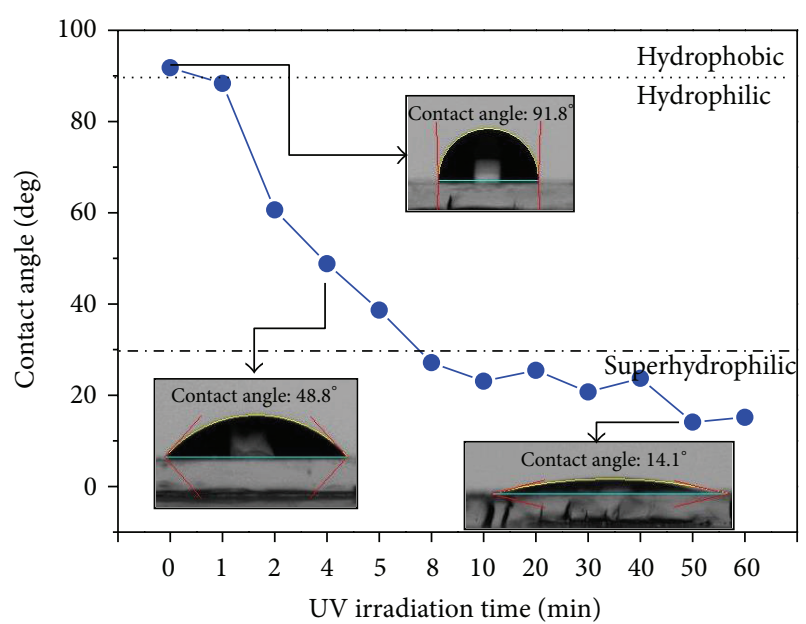

Figure 7: Time dependence of water contact angles (CAs) for the $\mathrm{ZnO}$ thin films deposited at $100 \mathrm{~W}$ under ultraviolet (UV) photoirradiation with the light wavelength of $365 \mathrm{~nm}$. Inset showed the corresponding water $\mathrm{CA}$ images accompanied with the measured values of the $\mathrm{ZnO}$ (0002) columnar films.

surface. The defective sites are kinetically more favorable for hydrophilic hydroxyl groups $\left(\mathrm{OH}^{-}\right)$adsorption than oxygen adsorption. In general, the oxygen adsorption is favorable in thermodynamic behavior; therefore, when the UV light irradiated $\mathrm{ZnO}$ film was moved to dark conditions, the oxygen atoms could gradually replace the hydroxyl groups which made the surface come back to its initial state (without UV photoirradiation) and return its original hydrophobicity. This behavior provides a foundation for photoresponse and the fraction structure enhances CA value. So the UV photoirradiation can modify the chemical and physical surface states of the $\mathrm{ZnO}$ columnar film, in turn switching its wettability. This is helpful in the research field focused on controllable switching behavior from superhydrophilicity (contact angle $\mathrm{CA}<15^{\circ}$ ) to hydrophobicity that can be used in many potential devices such as biosensors, microfluidic tools, intelligent membranes, and the encapsulation of biocompatibility/bioinertness in vivo biodevices [50-52].

The relationship between the time of storing in the dark varied from 10 to 600 mins and water CA values for the $\mathrm{ZnO}$ thin films deposited at $100 \mathrm{~W}$ as shown in Figure 8. Inset showed the corresponding water $\mathrm{CA}$ images accompanied with the measured values for the $\mathrm{ZnO}$ (0002) columnar film. The recovery time for the $\mathrm{ZnO}$ columnar film stored in the dark took about 10 hours to reach the initial/original water contact angle. The recovery behavior of the initial wettability is due to the surface discharging from the $\mathrm{ZnO}$ (0002) columnar film. The recovery behavior of hydrophobic surface from the $\mathrm{ZnO}$ columnar film is due to the replacement of adsorbed hydroxyl groups with oxygen molecules onto $\mathrm{ZnO}$ columnar film surface. After adsorbing hydroxyl groups under UV photoirradiation, the $\mathrm{ZnO}$ surface turns back to an unstable surface state. When the oxygen adsorption is preferred and strongly bonded on defective sites, the adsorbed hydroxyl groups on the defective sites could replace 


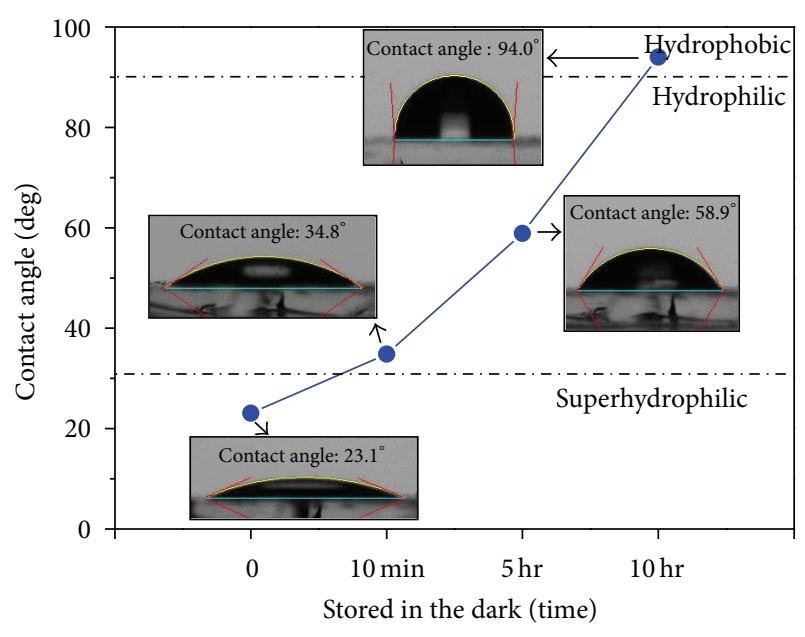

FIGURE 8: Stored in dark time dependence of water CAs for the $\mathrm{ZnO}$ thin films deposited at $100 \mathrm{~W}$ under UV photoirradiation. Inset showed the corresponding water CA images accompanied with the measured values of the $\mathrm{ZnO}$ (0002) columnar films.

oxygen molecules within the $\mathrm{ZnO}$ film stored in the dark environment. Above results demonstrate that the surface charge is strongly influenced by the UV photoirradiation.

\section{Conclusions}

Highly $c$-axis-oriented $\mathrm{ZnO}$ (0002) columnar films have been successfully deposited onto glass substrates at room temperature by radio-frequency magnetron sputtering system. All the $\mathrm{ZnO}$ columnar films exhibited good crystallinity and had good visible-averaged transparency (over 82\%), and all the $\mathrm{ZnO}$ films showed hydrophobic behavior. The wettability of the $\mathrm{ZnO}$ columnar film could be switched from hydrophobic $\left(\sim 92^{\circ}\right)$ to superhydrophilic $\left(\sim 14^{\circ}\right)$ during the UV photoirradiation process. The rapid transition of contact angle (CA) value for $\mathrm{ZnO}$ columnar film can be attributed to the photocatalytic behavior caused by the accumulation of positive surface charges via photoelectron emission. A simple method is presented here for controlling the CA value and switching wettability of $\mathrm{ZnO}$ phase only by the RF deposition power and inducing UV light photoirradiation, respectively.

\section{Conflict of Interests}

The authors declare that there is no conflict of interests regarding the publication of this paper.

\section{Acknowledgment}

The authors acknowledge financial support of the main research projects of the National Science Council of China under Grant nos. NSC 101-2622-E-027-003-CC2 and NSC 101-2221-E-027-042.

\section{References}

[1] D. H. W. Li, J. C. Lam, C. C. S. Lau, and T. W. Huan, "Lighting and energy performance of solar film coating in air-conditioned cellular offices," Renewable Energy, vol. 29, no. 6, pp. 921-937, 2004.

[2] Q. B. Ma, Z. Z. Ye, H. P. He et al., "Highly infrared reflective behavior of transparent conductive $\mathrm{ZnO}$ :Ga films synthesized by dc reactive magnetron sputtering," ChemPhysChem, vol. 9, no. 4, pp. 529-532, 2008.

[3] Z. Y. Huang, M. Chen, S. R. Pan, and D. H. Chen, "Effect of surface microstructure and wettability on plasma protein adsorption to $\mathrm{ZnO}$ thin films prepared at different RF powers," Biomedical Materials, vol. 5, no. 5, Article ID 54116, 2010.

[4] H. C. Barshilia, N. Selvakumar, N. Pillai, L. M. Devi, and K. S. Rajam, "Wettability of $\mathrm{ZnO}$ : a comparison of reactively sputtered; thermally oxidized and vacuum annealed coatings," Applied Surface Science, vol. 257, no. 9, pp. 4410-4417, 2011.

[5] H. Li, M. Zheng, S. Liu, L. Ma, C. Zhu, and Z. Xiong, "Reversible surface wettability transition between superhydrophobicity and superhydrophilicity on hierarchical micro/nanostructure $\mathrm{ZnO}$ mesh films," Surface and Coatings Technology, vol. 224, pp. 8892, 2013.

[6] K. Guan, "Relationship between photocatalytic activity, hydrophilicity and self-cleaning effect of $\mathrm{TiO}_{2} / \mathrm{SiO}_{2}$ films," Surface and Coatings Technology, vol. 191, no. 2-3, pp. 155-160, 2005.

[7] X. Feng and L. Jiang, "Design and creation of superwetting/antiwetting surfaces," Advanced Materials, vol. 18, no. 23, pp. 3063-3078, 2006.

[8] S. Wang, Y.-L. Song, and L. Jiang, "Photoresponsive surfaces with controllable wettability," Journal of Photochemistry and Photobiology C: Photochemistry Reviews, vol. 8, no. 1, pp. 18-29, 2007.

[9] N. Katsonis, M. Lubomska, M. M. Pollard, B. L. Feringa, and P. Rudolf, "Synthetic light-activated molecular switches and motors on surfaces," Progress in Surface Science, vol. 82, no. 78, pp. 407-434, 2007.

[10] G. Kenanakis, E. Stratakis, K. Vlachou, D. Vernardou, E. Koudoumas, and N. Katsarakis, "Light-induced reversible hydrophilicity of $\mathrm{ZnO}$ structures grown by aqueous chemical growth," Applied Surface Science, vol. 254, no. 18, pp. 5695-5699, 2008.

[11] M. N. Chong, B. Jin, C. W. K. Chow, and C. Saint, "Recent developments in photocatalytic water treatment technology: a review," Water Research, vol. 44, no. 10, pp. 2997-3027, 2010.

[12] Y. C. Lan, Y. L. Lu, and Z. F. Ren, "Mini review on photocatalysis of titanium dioxide nanoparticles and their solar applications," Nano Energy, vol. 2, pp. 1031-1045, 2013.

[13] R. Rosario, D. Gust, A. A. Garcia et al., "Lotus effect amplifies light-induced contact angle switching," Journal of Physical Chemistry B, vol. 108, no. 34, pp. 12640-12642, 2004.

[14] T. L. Sun, L. Feng, X. F. Gao, and L. Jiang, "Bioinspired surfaces with special wettability," Accounts of Chemical Research, vol. 38, no. 8, pp. 644-652, 2005.

[15] P. H. Yang, K. Wang, Z. W. Liang et al., "Enhanced wettability performance of ultrathin $\mathrm{ZnO}$ nanotubes by coupling morphology and size effects," Nanoscale, vol. 4, no. 18, pp. 5755-5760, 2012.

[16] E. Pakdel, W. A. Daoud, and X. G. Wang, "Self-cleaning and superhydrophilic wool by $\mathrm{TiO}_{2} / \mathrm{SiO}_{2}$ nanocomposite," Applied Surface Science, vol. 275, pp. 397-402, 2013. 
[17] K. Midtdal and B. P. Jelle, "Self-cleaning glazing products: a state-of-the-art review and future research pathways," Solar Energy Materials and Solar Cells, vol. 109, pp. 126-141, 2013.

[18] Y. B. Kwon, B. M. Weon, K. H. Won, J. H. Je, Y. Hwu, and G. Margaritondo, "X-ray-induced changes in wettability," Langmuir, vol. 25, no. 4, pp. 1927-1929, 2009.

[19] L. Q. Tang, B. Zhou, Y. M. Tian, F. Sun, Y. L. Li, and Z. C. Wang, "Synthesis and surface hydrophobic functionalization of $\mathrm{ZnO}$ nanocrystals via a facile one-step solution method," Chemical Engineering Journal, vol. 139, no. 3, pp. 642-648, 2008.

[20] P. Suresh Kumar, J. Sundaramurthy, D. Mangalaraj, D. Nataraj, D. Rajarathnam, and M. P. Srinivasan, "Enhanced superhydrophobic and switching behavior of $\mathrm{ZnO}$ nanostructured surfaces prepared by simple solution-immersion successive ionic layer adsorption and reaction process," Journal of Colloid and Interface Science, vol. 363, no. 1, pp. 51-58, 2011.

[21] X. M. Hou, L. X. Wang, F. Zhou, and L. Q. Li, "Fabrication of $\mathrm{ZnO}$ submicrorod films with water repellency by surface etching and hydrophobic modification," Thin Solid Films, vol. 519, no. 22, pp. 7813-7816, 2011.

[22] P. S. Kumar, J. Sundaramurthy, X. Zhang, D. Mangalaraj, V. Thavasi, and S. Ramakrishna, "Superhydrophobic and antireflecting behavior of densely packed and size controlled $\mathrm{ZnO}$ nanorods," Journal of Alloys and Compounds, vol. 553, pp. 375382, 2013.

[23] S. Anitha, B. Brabu, D. John Thiruvadigal, C. Gopalakrishnan, and T. S. Natarajan, "Optical, bactericidal and water repellent properties of electrospun nano-composite membranes of cellulose acetate and $\mathrm{ZnO}$," Carbohydrate Polymers, vol. 97, no. 2, pp. 856-863, 2013.

[24] X. Du and J.-H. He, "Structurally colored surfaces with antireflective, self-cleaning, and antifogging properties," Journal of Colloid and Interface Science, vol. 381, no. 1, pp. 189-197, 2012.

[25] G. Yakovlev, G. Pervushin, I. Maeva et al., "Modification of Construction Materials with Multi-Walled Carbon Nanotubes," Procedia Engineering, vol. 57, pp. 407-413, 2013.

[26] L. Gao, X. G. Li, H. Hu, G. J. Li, H. W. Liu, and Y. Yu, " $\mathrm{TiO}_{2}$ mesoporous microspheres with nanorod structure: facile synthesis and superior electrochemical performance," Electrochimica Acta, vol. 120, pp. 231-239, 2014.

[27] J. Godnjavec, J. Zabret, B. Znoj, S. Skale, N. Veronovski, and P. Venturini, "Investigation of surface modification of rutile $\mathrm{TiO}_{2}$ nanoparticles with $\mathrm{SiO}_{2} / \mathrm{Al}_{2} \mathrm{O}_{3}$ on the properties of polyacrylic composite coating," Progress in Organic Coatings, vol. 77, no. 1, pp. 47-52, 2014.

[28] V. Iliev, D. Tomova, S. Rakovsky, A. Eliyas, and G. L. Puma, "Enhancement of photocatalytic oxidation of oxalic acid by gold modified $\mathrm{WO}_{3} / \mathrm{TiO}_{2}$ photocatalysts under UV and visible light irradiation," Journal of Molecular Catalysis A: Chemical, vol. 327, no. 1-2, pp. 51-57, 2010.

[29] C. Song, P. Chen, C. Y. Wang, and L. Y. Zhu, "Photodegradation of perfluorooctanoic acid by synthesized $\mathrm{TiO}_{2}-\mathrm{MWCNT}$ composites under $365 \mathrm{~nm}$ UV irradiation," Chemosphere, vol. 86, no. 8, pp. 853-859, 2012.

[30] V. R. Shinde, C. D. Lokhande, R. S. Mane, and S. Han, "Hydrophobic and textured $\mathrm{ZnO}$ films deposited by chemical bath deposition: annealing effect," Applied Surface Science, vol. 245, no. 1-4, pp. 407-413, 2005.

[31] P. S. Kumar, A. D. Raj, D. Mangalaraj, and D. Nataraj, "Hydrophobic $\mathrm{ZnO}$ nanostructured thin films on glass substrate by simple successive ionic layer absorption and reaction
(SILAR) method," Thin Solid Films, vol. 518, no. 24, pp. e183e186, 2010.

[32] Y. Z. Yang, C. X. Wang, H. D. Li, and Q. Lin, "Ultrahydrophobicity of $\mathrm{ZnO}$ modified CVD diamond films," Applied Surface Science, vol. 270, pp. 260-266, 2013.

[33] J. J. Hassan, M. A. Mahdi, C. W. Chin, H. Abu-Hassan, and Z. Hassan, "A high-sensitivity room-temperature hydrogen gas sensor based on oblique and vertical $\mathrm{ZnO}$ nanorod arrays," Sensors and Actuators B: Chemical, vol. 176, pp. 360-367, 2013.

[34] C. L. Hsu, K. C. Chen, T. Y. Tsai, and T. J. Hsueh, "Fabrication of gas sensor based on p-type $\mathrm{ZnO}$ nanoparticles and n-type $\mathrm{ZnO}$ nanowires," Sensors and Actuators B Chemical, vol. 182, pp. 190196, 2013.

[35] V. A. Minh, L. A. Tuan, T. Q. Huy, V. N. Hung, and N. V. Quy, "Enhanced $\mathrm{NH}_{3}$ gas sensing properties of a QCM sensor by increasing the length of vertically orientated $\mathrm{ZnO}$ nanorods," Applied Surface Science, vol. 265, pp. 458-464, 2013.

[36] Y. N. He, W. Zhang, S. C. Zhang, X. Kang, W. B. Peng, and Y. L. $\mathrm{Xu}$, "Study of the photoconductive $\mathrm{ZnO} \mathrm{UV}$ detector based on the electrically floated nanowire array," Sensors and Actuators A: Physical, vol. 181, pp. 6-12, 2012.

[37] C. H. Chao, M. Y. Chen, C. R. Lin, Y. C. Yu, Y. D. Yao, and D. H. Wei, "Postannealing effect at various gas ambients on ohmic contacts of $\mathrm{Pt} / \mathrm{ZnO}$ nanobilayers toward ultraviolet photodetectors," International Journal of Photoenergy, vol. 2013, Article ID 372869, 9 pages, 2013.

[38] N. K. Hassan and M. R. Hashim, "Flake-like $\mathrm{ZnO}$ nanostructures density for improved absorption using electrochemical deposition in UV detection," Journal of Alloys and Compounds, vol. 577, pp. 491-497, 2013.

[39] L. J. Wang and G. J. Exarhos, "Persistent conductivity in postgrowth doped $\mathrm{ZnO}$ films following pulsed UV laser irradiation," Thin Solid Films, vol. 519, no. 5, pp. 1495-1500, 2010.

[40] V. Eskizeybek, F. Sari, H. Gülce, A. Gülce, and A. Avci, "Preparation of the new polyaniline/ $\mathrm{ZnO}$ nanocomposite and its photocatalytic activity for degradation of methylene blue and malachite green dyes under UV and natural sun lights irradiations," Applied Catalysis B: Environmental, vol. 119-120, pp. 197-206, 2012.

[41] X. J. Liu, L. K. Pan, Q. F. Zhao et al., "UV-assisted photocatalytic synthesis of $\mathrm{ZnO}$-reduced graphene oxide composites with enhanced photocatalytic activity in reduction of $\mathrm{Cr}(\mathrm{VI})$," Chemical Engineering Journal, vol. 183, pp. 238-243, 2012.

[42] P. Pradhan, J. C. Alonso, and M. Bizarro, "Photocatalytic performance of $\mathrm{ZnO}$ : al films under different light sources," International Journal of Photoenergy, vol. 2012, Article ID 780462, 7 pages, 2012.

[43] X. L. Zhang, K. S. Hui, and K. N. Hui, "High photo-responsivity $\mathrm{ZnO}$ UV detectors fabricated by RF reactive sputtering," Materials Research Bulletin, vol. 48, no. 2, pp. 305-309, 2013.

[44] Y. H. Mun, S. H. Park, S. Y. An, C. M. Lee, and H. W. Kim, " $\mathrm{NO}_{2}$ gas sensing properties of $\mathrm{Au}$-functionalized porous $\mathrm{ZnO}$ nanosheets enhanced by UV irradiation," Ceramics International, vol. 39, pp. 8615-8622, 2013.

[45] R. G. Zhang, B. Y. Wang, and L. Wei, "Influence of RF power on the structure of $\mathrm{ZnS}$ thin films grown by sulfurizing RF sputter deposited ZnO," Materials Chemistry and Physics, vol. 112, no. 2, pp. 557-561, 2008.

[46] X. H. Yu, J. Ma, F. Ji et al., "Effects of sputtering power on the properties of $\mathrm{ZnO}$ :Ga films deposited by r.f. magnetronsputtering at low temperature," Journal of Crystal Growth, vol. 274, no. 3-4, pp. 474-479, 2005. 
[47] J. Han and W. Gao, "Surface wettability of nanostructured Zinc oxide films," Journal of Electronic Materials, vol. 38, no. 4, pp. 601-608, 2009.

[48] D. Wu, Q. D. Chen, H. Xia et al., "A facile approach for artificial biomimetic surfaces with both superhydrophobicity and iridescence," Soft Matter, vol. 6, no. 2, pp. 263-267, 2010.

[49] A. Nakajima, K. Hashimoto, T. Watanabe, K. Takai, G. Yamauchi, and A. Fujishima, "Transparent superhydrophobic thin films with self-cleaning properties," Langmuir, vol. 16, no. 17, pp. 7044-7047, 2000.

[50] Y. Liu, Z. Lin, W. Lin, K. S. Moon, and C. P. Wong, "Reversible superhydrophobic-superhydrophilic transition of ZnO nanorod/epoxy composite films," ACS Applied Materials and Interfaces, vol. 4, no. 8, pp. 3959-3964, 2012.

[51] C. Mondal, M. Ganguly, A. K. Sinha, J. Pal, and T. Pal, "Fabrication of a $\mathrm{ZnO}$ nanocolumnar thin film on a glass slide and its reversible switching from a superhydrophobic to a superhydrophilic state," RSC Advances, vol. 3, no. 17, pp. 59375944, 2013.

[52] W. H. Liao, C. R. Lin, D. H. Wei et al., "Concurrent improvement in biocompatibility and bioinertness of diamond-like carbon films with nitrogen doping," Journal of Biomedical Materials Research A, vol. 100, no. 11, pp. 3151-3156, 2012. 

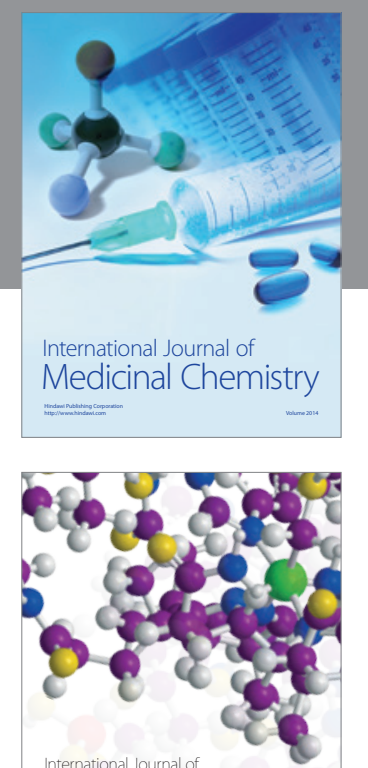

\section{Carbohydrate} Chemistry

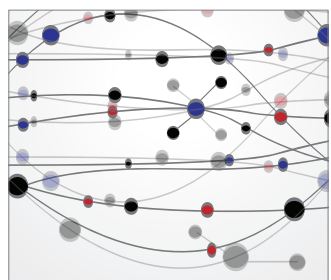

The Scientific World Journal
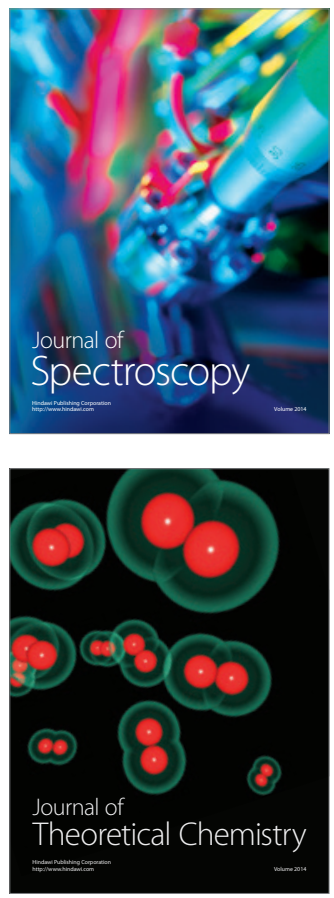
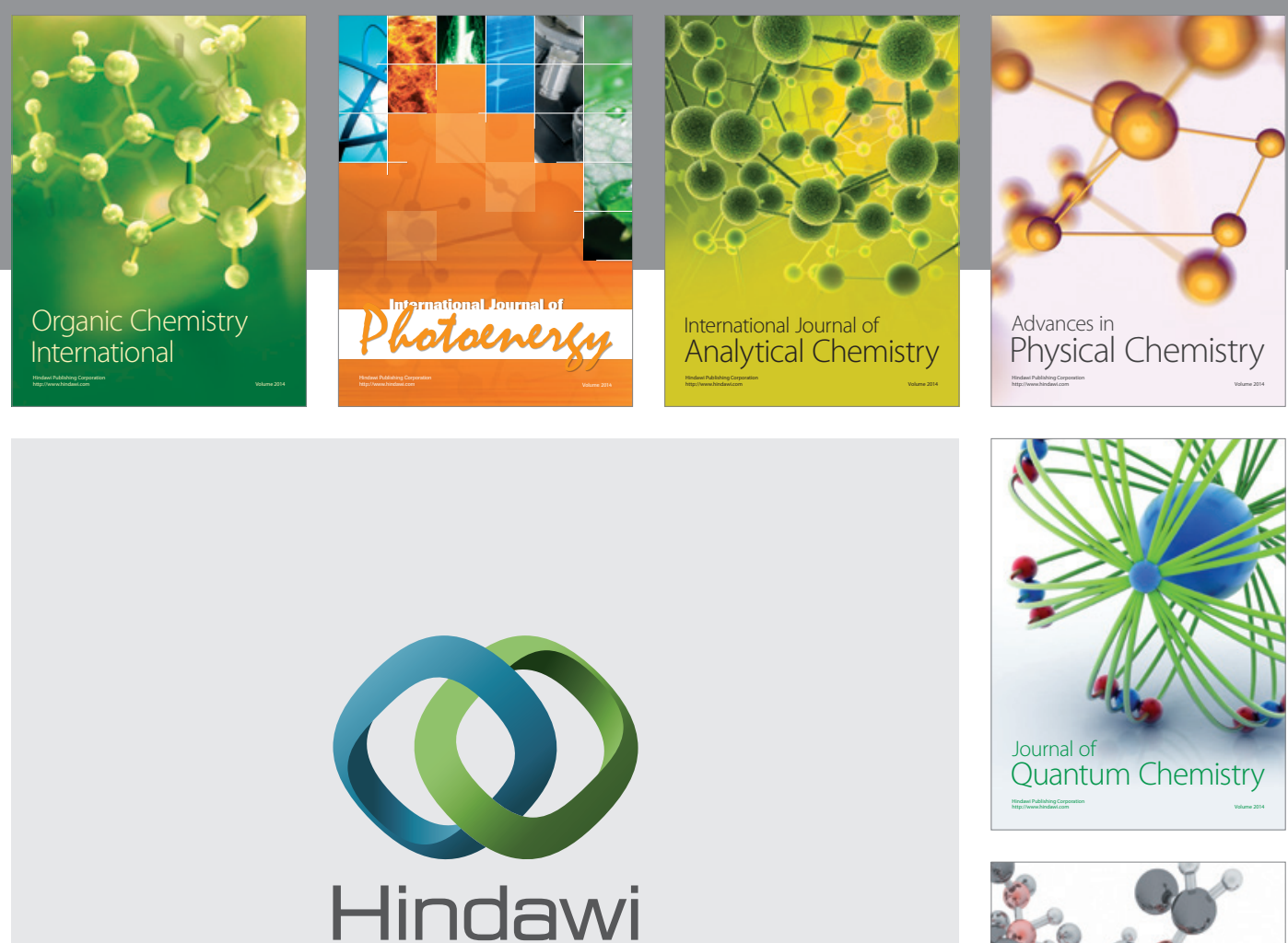

Submit your manuscripts at

http://www.hindawi.com

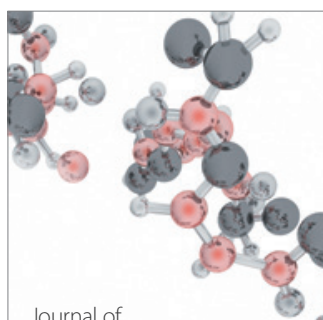

Analytical Methods

in Chemistry

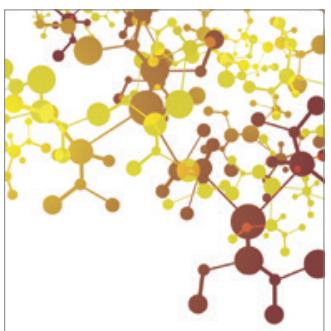

Journal of

Applied Chemistry

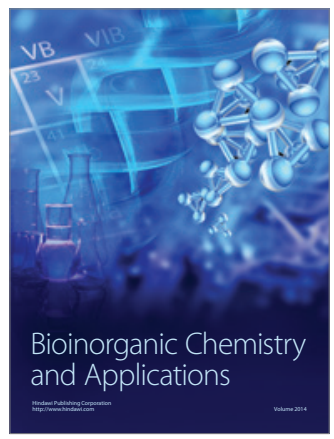

Inorganic Chemistry
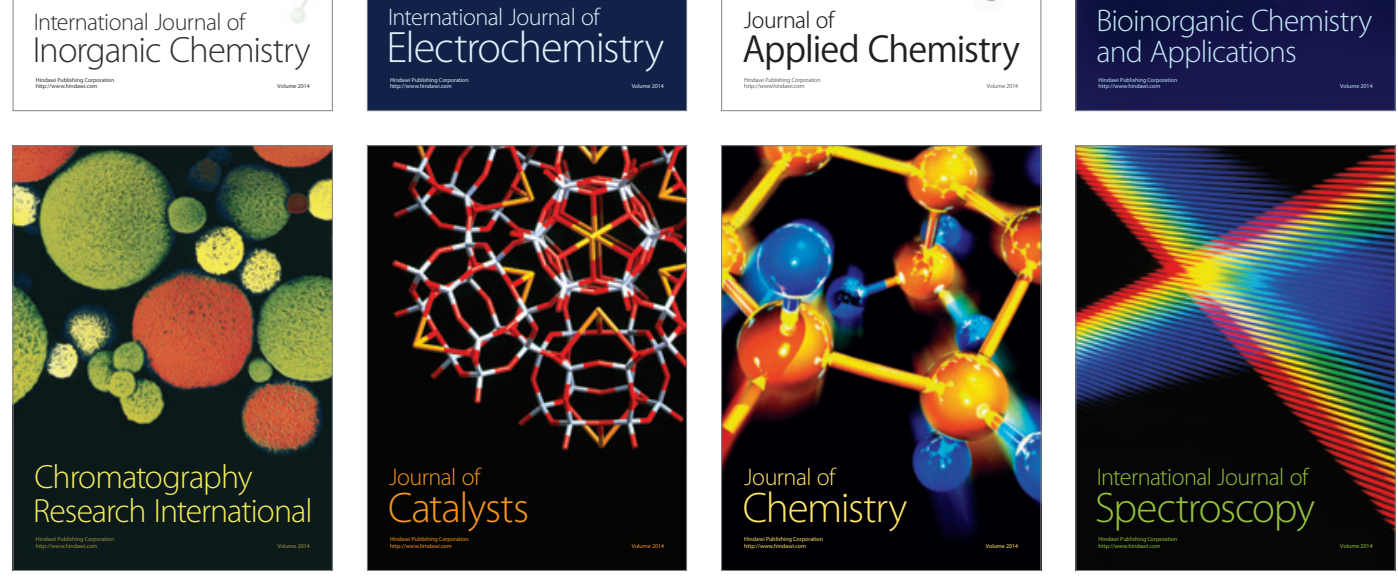